\title{
Eutanasia:
}

Byron Silva

\section{Felici vel honesta morte mori}

\section{Un perro que muere y sabe que muere $y$} puede decir que sabe que muere como un perro, es un hombre. ${ }^{l}$

Hace frío. Es un día lluvioso. El cielo ha bajado como si pretendiera ahogar a la tierra. Gotas sin esperanza caen desoladamente gruesas. La pequeña cafetería de la Universidad está repleta. Los vidrios empañados. Voces alrededor: Un café y un brownie, por favor, A mi me da un sánduche, ¿Cuánto cuesta un jugo?, Una botella de agua, porfa. He ahí los alimentos que aplacarán el hambre de la primera hora. Hay quienes bien despiertos y mal sentados apuran su desayuno con un cigarrillo que humea a dueto con el café caliente. El cigarrillo en el cenicero, el café en la tasa. En el fondo del local, al lado de la ventana, sobre una estrecha y pesada mesa, algunos estudiantes han madrugado a discutir acaloradamente. Por una noticia de periódico.

- Estoy seguro - dijo el Sapo con gran énfasis- que tú, yo y todo mundo desea morir, como decían los antiguos romanos, de forma feliz, decente, o sea, tranquila y sin sufrimiento. ¿O es que acaso tú anhelas morir llena de sufrimientos y angustiando a los demás? ¿Quién no prefiere tener una buena muerte? ¿Por qué, entonces, sería ilícito evitar con la muerte los sufrimientos a una persona que no tiene posibilidad de vivir, que ya no quiere vivir?

- Tienes razón, pero de cualquier forma que lo pintes, para mí, la eutanasia es un asesinato, por más que el parlamento holandés, una corte británica, un tribunal español o lo que sea, lo aprueben en una ley o en una sentencia. - espetó Maríagracia en la cara del Sapo-Siempre ha sido un crimen, aunque el mismo enfermo lo pida, porque siempre queda la duda de que pueda recobrar la salud y, sobre todo, porque la vida es un don divino del que no se puede disponer así nomás. Si quieres remontarte a los antiguos te menciono de pasada, sin querer pecar de erudita, lo que dejo dicho Hipócrates, más o menos: No daré ningún veneno a nadie, aunque me lo pidan, ni tomaré nunca la iniciativa de sugerir tal cosa. Además, eso de buena muerte no significa lo mismo para todo mundo.

- Ya -interrumpió el Sapo-. Pero también se debe tomar en cuenta al sabio Platón que aconsejaba que el Estado debe cuidar de quienes gozan de salud de alma y cuerpo y que se debe dejar morir a quienes no sean sanos de cuerpo. $\mathrm{O}$ sea, que no tiene mucho sentido mantener vivas a personas que desde hace rato pueden y, sobre todo, quieren morir. En la Grecia y la Roma antiguas había una amplia aceptación en la práctica de la eutanasia. Fueron el judaísmo y el cristianismo los que contribuyeron, en mi opinión de forma contradictoria, a difundir la noción absoluta de la santidad de la vida humana y de que uno no puede privarse de la vida de manera deliberada. No te olvides que, sin embargo, los mismos cristianos unas veces murieron por la fe y otras, las más, mataron por la fe.

- ¡Por favor! ¿Qué dicen, queridos? - interrumpió la Flaca poniendo cara de asco- Con lo dura que es la vida, con todo lo que me cuesta mantenerme bella y hermosa, ¿por qué no darme una buena muerte si está al alcance de mis manos? Más fácil y sin resucitar a tantas antigüedades. - Meneaba su cabeza de una lado a otro, interrogante, las manos abiertas para arriba.

Se quedaron todos mudos, las cejas en alza. Con los ojos fuera la miraban. Así era la Flaca. Descomplicada. Pragmática. Una preciosa.

Intervino Isaías.

- No me acusen, por favor, como otras veces, de relativista. Creo que todos tienen algo de razón a su manera. Se trata, simplemente, de poner las cosas en su lugar y de aclarar el punto de cada uno. —-sentenció.

Isaías ya olía a catedrático.

Por un momento el tono de la discusión bajó. El Sapo, Maríagracia y la Flaca pusieron atención a lo que Isaías tenía que decirles. Los curiosos de la mesa de al lado apuntaron la oreja en esa dirección. Por un instante hubo silencio. ¿Se detuvo el tiempo?

A partir del 1 de abril de 2002, Holanda es el primer país que permite la práctica de la eutanasia activa.

Para que tal práctica no constituya delito, la nueva ley holandesa exige el cumplimiento de los siguientes requisitos: 1) que el enfermo esté sometido a un sufrimiento insoportable sin que exista perspectiva de mejora alguna; 2) que el desahuciado exprese de forma categórica e inequívoca su voluntad de cesar en la vida; 3 ) que se cuente con la opinión de otro médico; y 4) que el facultativo que ayudó a morir informe de inmediato a una de las comisiones de ética para que estudie el caso y juzgue si se han respetado los requisitos precedentes. En caso contrario, la comisión tiene la obligación de informar al ministerio fiscal para que se siga la acción penal correspondiente.

La mencionada ley introduce también dos novedades en relación con la jurisprudencia que desde 1973 vienen sancionando los tribunales holandeses: 1) el testamento vital, que es una declaración previa por parte de aquellos moribundos que en el último momento no tienen capacidad para manifestar su deseo de morir, y 2) la posibilidad de que los menores a partir de los 16 años de edad puedan pedir la eutanasia activa sin autorización previa de sus progenitores. 
La novedosa eutanasia legal viene, entonces, a distinguirse de otras formas de quitar la vida que son consideradas delito: el homicidio o asesinato y el suicidio, entre las conductas más claramente distintas de la eutanasia, y el homicidio piadoso y el suicidio asistido, entre las conductas más cercanas a la eutanasia y, por tal circunstancia, que suelen confundirse con ésta.

Isaías tenía el sano hábito de distinguir para unir. Era un chico ensimismado, descuidado, melancólico, despistado. Como Tales de Mileto, un día caminando con un grupo de amigos por el parque cayó en un hueco que el municipio había hecho para reparar el alcantarillado. Afortunadamente sólo sufrió leves rasguños. Sus amigos de burlaron de él. Eso fue lo que más le dolió. Desde entonces la apodaron el Sabio. Cada vez que le llamaban así se renovaba su vergüenza.

Continuó Isaías.

- Maríagracia, desde tu perspectiva, sostienes que la eutanasia es un crimen. En efecto, el cristianismo introduce en la historia de la civilización occidental el mandato divino: No matarás y cualquier conducta que viole este precepto es considerado un crimen. Para los católicos, según tengo entendido, la eutanasia es gravemente ilícita. En su modo de pensar el respeto absoluto a la vida de la persona humana es superior a cualquier forma de compasión. El hombre no es dueño de su vida, dicen. En cambio, para otras personas que no comparten los mismos valores del cristianismo, como el Sapo, la compasión, la piedad, la misericordia ante el dolor del ser querido relativizan ese respeto a la vida humana, pues una vida que no es vida no merece ser vivida, sostienen. $Y$ hay quienes consideran, en esto me refiero a las palabras de la Flaca, como valor supremo de conducta el principio de autonomía, según el cual, decidir el destino de cada persona corresponde exclusivamente a esa misma persona y a nadie más.

La Flaca quedó agradecida. Casi nunca sus ideas eran tomadas en cuenta. Quiso decir algo, devolver la cortesía, pero el ímpetu de Maríagracia le dejó con las palabras atrapadas entre la lengua y los dientes. Hizo una mueca y se calló.

- Es verdad - dijo Maríagracia — no todos pensamos del mismo modo, pero los derechos humanos, y el de la vida es el más importante, escapan a un pluralismo que en otros temas es legítimo, pero que no puede admitirse en cuestiones que son, nunca mejor dicho, de vida o muerte. Hay un orden natural en las cosas. Hay una ley natural que prohíbe matar de forma categórica. No puede pensarse, por tanto, el derecho a la vida como algo relativo, objeto de consideraciones subjetivas. Por eso, pese a las razones sentimentales, humanas, económicas y sociales, la eutanasia es siempre ilícita y, desde la perspectiva del derecho, injurídica por violar uno de los preceptos fundamentales de la ley natural, garantizado en las constituciones políticas de los estados de derecho contemporáneos. Por eso, también el suicidio es absolutamente ilícito, pues, al decir de Immanuel Kant, el hombre no puede tener la facultad de quitarse la vida.
Afuera, mientras Maríagracia pontificaba, se desataba la furia del cielo, llovía más fuerte, como si la Ciudad de Dios quisiera destruir la Ciudad de los Hombres. La Flaca dibujaba en el vidrio empañado de la ventana un corazón, una espada y un martillo. Debajo del corazón escribió Sapo, debajo de la espada Sabio y debajo del martillo Maríagracia. Así eran sus amigos o, al menos, ella los veía así.

- Y tú, ¿qué haces? —dijo molesta Maríagracia dirigiéndose a la Flaca al término de su argumentación.

- No, nada — contestó ella mientras borraba con la manga los dibujos que había hecho en el vidrio.

El Sapo se sintió atacado. No podía quedarse callado. Quería destruir la raíz misma del argumento de su compañera. Se aprestaba a hacerlo; cuando Isaías que pensaba en lo mismo, pero por otros motivos, se anticipó.

- Las objeciones a la eutanasia no son morales sino religiosas. -comenzó Isaías-. Todos tus argumentos, Maríagracia, se fundan en tu religión católica. Y no todos abrazamos esa fe. Me parece importante, por tanto, para beneficio del debate, señalar que la moral y la religión son dos sistemas independientes, de manera que no existe dependencia lógica de la moral respecto de la religión. La religión no es condición necesaria ni suficiente de la moral. La independencia de la moral y de la religión indicaba Isaías con movimientos de la mano derecha donde el dedo índice era el protagonista - nos permite valorar de forma distinta varias situaciones que el carácter absoluto de la religión impide hacerlo. Esa independencia es, además, importante para las consideraciones de orden jurídico, pues las convicciones religiosas son dignas de respeto pero no hasta el extremo de imponerse a través de la legislación a otras personas que no las profesan. Recuerden que el orden jurídico está dirigido a creyentes y no creyentes, y sus instituciones deben dejar suficiente libertad a unos y otros. Desde el siglo XVII los filósofos ingleses que pensaron el Estado liberal (Hume, Bentham y Stuart Mill, en particular) cuestionaron la base religiosa de la moralidad y la prohibición absoluta del suicidio y la eutanasia.

Nadie se esperaba que Isaías fuera tan categórico en este punto.

\section{$* \quad * \quad *$}

Puesto que los hombres se asocian mediante el discurso, y una mala e inadecuada imposición de nombres mantiene ocupado el entendimiento de manera asombrosa, así pues las palabras ejercen una extraordinaria violencia sobre el entendimiento y perturban todo.2

En nuestras inacabables discusiones a menudo no nos damos cuenta de que en realidad hemos llegado a un acuerdo; lo que sucede es que llamamos a las mismas cosas con nombres distintos. $Y$, al contrario, ocurre que las contradicciones más profundas se ocultan alli donde no las vemos, llamando por costumbre cosas completamente distintas con el mismo nombre. ${ }^{3}$

Con la palabra eutanasia sucede lo anotado. La etimología de esta palabra es muy simple pero, por eso mismo, complejo su significado. Proviene del griego $e u-b i e n-y$ thanatos - muerte-, que unidos significa buena muerte. 
Para algunos buena muerte significa liberar a una persona de los sufrimientos poniendo fin a su vida (eutanasia activa). Para otros significa dejar morir a una persona retirándole el tratamiento que le mantiene con vida (eutanasia pasiva). Hay quienes entienden la eutanasia como ortotanasia (orto: recto, normal), es decir, como muerte justa, normal, a su debido tiempo.

Si se cuenta o no con el interés, requerimiento o consentimiento del moribundo, la muerte provocada de manera activa puede ser: 1) homicidio o asesinato, en caso de que otra persona ocasione la muerte sin el interés, requerimiento o consentimiento del afectado; y 2) suicidio o eutanasia, cuando se cuenta con tal interés, requerimiento o consentimiento.

Si la conducta que procura la muerte está ordenada a la eliminación del sufrimiento o de unas condiciones de vida no aceptables, anormales, esa conducta se denomina eutanasia propiamente dicha. Si falta ese objetivo la conducta será homicidio, asesinato o suicidio pero no eutanasia.

En el ámbito de la eutanasia pasiva se distinguen conductas que constituyen homicidio por omisión o negligencia de otras conductas que reciben el nombre de distanasia, por consistir en la omisión de los medios considerados extraordinarios o desproporcionados para sostener la vida de un enfermo desahuciado irreversible (muerte penosa).

Estas nociones se complican cuando se ponen junto a la palabra eutanasia los adjetivos directa, indirecta, positiva, negativa, voluntaria, involuntaria, no voluntaria.

Así pues, se ha producido violencia en el entendimiento de la eutanasia (contradicciones e inacabables discusiones) cuando, para fines de valoración moral, sobre todo, desde la moral religiosa, se confunde la eutanasia con otras conductas. Pues unas veces se habla de eutanasia homicida, otras de eutanasia suicida, en ocasiones eutanasia eugenésica (eliminación de vidas sin valor). Obviamente, con esos nombres estas conductas necesariamente revisten un sentido de ilegitimidad. La misma moral religiosa llama a conductas que constituyen eutanasia con nombres distintos con el fin de declararlos legítimos. Así a algunas formas de eutanasia indirecta se las llama muerte sin dolor, en donde no se procura ni se detiene la muerte sino que se administra analgésicos aunque estos disminuyen el tiempo de vida del enfermo. Otras formas de eutanasia pasiva cuentan con una valoración positiva por parte de la moral religiosa y para tal efecto se les da un nuevo nombre: distanasia.

El problema de la eutanasia ha venido a complicarse cuando de forma innecesaria los moralistas introdujeron infinidad de clases y más clases de eutanasias y cuando recurrieron a la palabra eutanasia para designar realidades distintas e incluso contrapuestas.

Se produjo una fuerte tensión entre Maríagracia e Isaías. El Sapo quedó satisfecho con la réplica de su compañero. Para calmar los ánimos se refirió a otro problema de la eutanasia.

- La eutanasia viene a ser un problema social y jurídico comenzó el Sapo-- sobre todo en las sociedades que han alcanzado un alto nivel de vida y de asistencia médica pública y privada. Esos países cuentan no sólo con los medios necesarios para mantener la vida de los enfermos terminales sino también con los innecesarios que pueden alargar excesivamente una vida de sufrimiento. En cambio, en países como los nuestros con niveles de vida muy bajos que no satisfacen ni siquiera las necesidades básicas de la mayoría de habitantes, la eutanasia no ha entrado a la discusión pública del mismo como en los países industrializados. En nuestro lindo Ecuador, por ejemplo, se sigue discutiendo sobre las carencias del sistema de salud pública y de la falta de una ley que castigue las malas prácticas médicas.

Esta fue la ocasión para que la Flaca soltara uno de sus preciosos molones.

- Ahí no te doy la razón, querido Sapito — dijo la Flaca, meneándose con aires profesorales. - En nuestro país estamos más adelantados en materia de eutanasia que Holan$\mathrm{da}$, sólo que no nos damos cuenta. Somos tan asombrosos que hemos inventado y legitimado por fuerza de la costumbre la eutanasia pública gratuita que es la que se practica en todos en los hospitales públicos y en los del Instituto Ecuatoriano de Seguridad Social, por carencia de me dios, por indolencia de los burócratas de turno o por huelga de los funcionarios y trabajadores que reclaman el cumplimiento de sus sagrados derechos relegados al quemeimportismo del Gobierno desde hace años. No se entiende cómo llegamos a tal extremo —concluyó la Flaca-, por eso mismo un buen amigo mío decía que para explicar lo que sucede en el Ecuador el lenguaje solito no es suficiente.

Otra vez sus amigos quedaron mudos. Ocurrida y profunda estaba la Flaca.

En el ámbito del Derecho actualmente se discute sobre la existencia del derecho constitucional a la buena muerte, como una determinación del derecho a la vida y el principio jurídico de la autonomía.

Algunos ordenamientos jurídicos, a través de los tribunales, han sentado jurisprudencia. En 1993, la Cámara de Lores permitió la eutanasia fundándose sobre lo que llamó la doctrina del mejor interés, según la cual no es benéfico para un paciente permanecer en estado vegetativo, ya que el principio relativo a la vida sagrada no es absoluto. Otros tribunales han invocado el derecho a la privacidad, el derecho a informar respecto a consentir la continuidad o no de un tratamiento médico. En Colombia, la Corte Constitucional declaró en 1997 que en el caso de los enfermos terminales en que concurra la voluntad libre del sujeto pasivo del acto, no podrá derivarse responsabilidad penal para el médico autor, pues la conducta está justificada. ${ }^{4}$

La Corte Constitucional colombiana fundó su fallo en la siguiente consideración: la decisión de cómo enfrentar la muerte adquiere una importancia decisiva para el enfermo terminal, que sabe que no puede ser curado, y que por ende no está optando entre la muerte y muchos años de vida plena, sino entre morir en condiciones que él escoge o morir poco tiempo después en circunstancias dolorosas que juzga indignas. El derecho fundamental a vivir en forma digna implica entonces el derecho a morir dignamente, pues condenar a una persona a prolongar por tiempo escaso su existencia, cuando no lo desea y padece profundas aflicciones, equivale no solo a un trato cruel e inhumano, prohibido por la Carta (C. P. art. 12), sino a una anulación de su dignidad y de su autonomía como sujeto moral. La persona quedaría reducida a un instrumento para la preservación de la vida como valor abstracto. 
La Constitución Política del Ecuador establece, por una parte, el derecho a la inviolabilidad de la vida y, por otra, la prohibición de todo procedimiento inhumano, degradante o que implique violencia. La comprensión de la eutanasia según tales disposiciones no es tarea fácil. Si la eutanasia es siempre considerada como una violación de la vida, entonces nuestra Constitución excluiría en toda circunstancia, por injurídica, la práctica de la eutanasia, con mayor razón si además ésta es calificada como procedimiento inhumano, degradante o violento.

Sin embargo las mismas disposiciones constitucionales podrían permitir la práctica legal de ciertas formas jurídicas de eutanasia, en el entendido de que el derecho a la inviolabilidad a la vida tendría como corolario lógico el derecho a decidir libremente sobre el fin de la propia vida (principio de autonomía), y cuando el mantenimiento de la vida en forma artificial derive en procedimientos inhumanos, degradantes o que provoquen excesivo sufrimiento o dolor al enfermo o desahuciado.

Este debate no se ha abierto en Ecuador a la discusión pública, en parte porque la hegemonía que la moral católica tiene en nuestra idiosincrasia impide siquiera plantearlo.

- Dejando de lado la observación del Sapo y la ocurrencia de la Flaca — continuó Isaías - en lo profundo del debate sobre la eutanasia se halla el sentido de la vida y el sentido de la muerte — subrayaba en el aire estas palabras mientras las pronunciaba-, en definitiva, la visión que cada uno tiene de sí mismo. Por eso es imposible conciliar, sin conflicto, la solución legal de la eutanasia con la moralidad individual de cada persona. Hoy por hoy, la eutanasia se presenta como un problema insoluble. Porque además en este problema cuenta tanto la moral individual del paciente desahuciado como la moral del médico tratante que podría entrar en conflicto.

Maríagracia no cedía en su punto de vista. Para ella el problema de la eutanasia no era insoluble sino, al contrario, claramente resuelto en los términos de la moral católica.

- Mira Isaías - tomó la palabra Maríagracia-, en otros tiempos, todo el mundo estaba de acuerdo en rechazar la práctica de la eutanasia, pues matar a una persona siempre era considerado delito. Esto ha sido así y deber seguir siendo así, porque al hombre no le es lícito disponer de su propia vida, peor de la vida de otro. El médico, por su parte, está para curar y no para matar. Si se legaliza la práctica de la eutanasia se pondría en peligro la vida de personas débiles que no pueden valerse por sí mismas, ya por estar gravemente enfermas o disminuidas notablemente. Podrían darse abusos en que los parientes, cansados de atenderlas o con interés de heredar rápidamente, deseen terminar con sus vidas a título de muerte piadosa. Me ratifico en que no debe permitirse la legalización de la eutanasia, por ser gravemente inmoral. Es más, pienso que debería ser penalizada.

- Ese ha sido - reaccionó rápidamente Isaías - , precisamente, el problema de los mesianismos políticos y de las religiones, especialmente de la católica: querer edificar la Ciudad de Dios, la Verdad, aquí abajo en el tiempo. Por eso la historia ha sido tan sangrienta. Acuérdate de las Cruzadas, de la Inquisición, de la Conquista.
Nunca el Sapo había sentido tantas ganas como ahora de decirle unas cuantas cosas a su compañera Maríagracia.

- ¿Estás segura que tus argumentos teológicos son plenamente convincentes para el enfermo desahuciado que sufre grandes dolores? Te concedo que la vida humana es un don de Dios. Pero, ¿no es a la vez la vida, por voluntad de Dios, responsabilidad de la persona humana? Admito que el hombre tiene la obligación de aguantar hasta el fin dispuesto por Dios. Pero, ¿cuál es el fin dispuesto y quién es competente para determinarlo sino quien es responsable de sí mismo? Precisamente porque el hombre es y permanece hombre hasta el momento mismo de su muerte, tiene derecho a una vida humana y a una muerte humana. A diferencia del perro, sólo el hombre conoce que morirá y en consecuencia tiene derecho y capacidad para morir humanamente y no como perro, aunque en algunas circunstancias, de hecho, muera como perro. Ya va siendo hora que el problema de la eutanasia sea liberado de la zona de los tabúes teológicos donde se encuentra prisionero desde hace más de dos mil años.

- Ya va siendo hora de irse -interrumpió bruscamente la Flaca el argumento de su amigo el Sapo, mientras espiaba a través de la ventana-, está escampando y hay que ir a clases. Ya está bien de hablar de temas complicados y hasta cierto punto inútiles. Dejemos de preocuparnos por la muerte. Ahora ocupémosno de disfrutar de la vida. Cuando seamos viejos nos hemos de aplicar a tales especulaciones.

La Flaca fue la primera en levantarse.

La discusión terminó. La lluvia también. Discretamente aparecía el sol. Nuestros amigos recogieron sus bártulos y abandonaron la estrecha y pesada mesa. Salieron de la cafetería como entraron, con las mismas convicciones.

$\mathrm{Al}$ apuro, saltando entre charco y charco, se dirigieron a recibir sus clases. Isaías, en solitario, la cabeza en las nubes, rumiaba sus argumentos. Llegó al aula atrasado y con los zapatos empapados.

Mientras tanto, la cafetería iba quedando vacía y languidecía por falta de ruido. La dependiente, como alma que lleva el diablo, saltó del mostrador y corrió a encender la televisión que se hallaba dormida en el soporte. Por lo que se vio, le aterraba el silencio, lo más cercano a la muerte mientras se vive.

Por mi parte, antes de ir a trabajar, me quedé un rato más en la cafetería. Tomé un sorbo de café, aspiré el cigarro. Me dejé hechizar por los ruidos de MTV y los sensuales movimientos de la voluptuosa Britney Spears.

Ahora que finalizo esta memoria, en el libro que tengo enfrente de casualidad alcanzo a leer:

Que te acoja la muerte

con todos tus sueños intactos. .

Al retorno de una furiosa adolescencia,

al comienzo de las vacaciones que nunca te dieron,

te distinguirá la muerte con su primer aviso.

Te abrirá los ojos a sus grandes aguas, te iniciará en su constante brisa de otro mundo.

La muerte se confundirá con tus sueños

y en ellos reconocerá los signos

que antaño fuera dejando,

como un cazador que a su regreso

reconoce sus marcas en la brecha. ${ }^{6}$

Quito, abril - mayo de 2002 
Notas 1) E. Fried, citado por Hans Küng, ¿Vida Eterna?, Trotta, Madrid, 2000, pág. 267.

2) Bacon Francis, Novum organum scientiarum, Sección II, Aforismo VI.

3) Guerasimchuk Ivetta, Diccionario de los Vientos, Galaxia Gutenberg/Círculo de Lectores, Barcelona, 2001, pág.16.

4) Citado en Ilva Myriam Hoyos Castañeda, La persona y sus derechos. Consideraciones bioéticas - jurídicas, Temis, Bogotá, 2000, pág. 150.

5) Idem, pág. 152

6) Mutis Álvaro, Suma de Maqroll el Gaviero. Poesía 1948-1988, Fondo de Cultura Económica, México, 1995, pág. 65.

Bibliografía

Cortina, Adela, Ética aplicada y democracia radical, Tecnos, Madrid, 1993.

Diario El País, www.elpais.es, 2001, 2002.

Facorro, Susana J. - Vittadini, Susana N., Dogmática Constitucional, Abeledo Perrot, Buenos Aires, 1999.

García-Sabell, Domingo, Paseos alrededor de la muerte, Alianza, Madrid, 1999.

Hoyos Castañeda, Ilva Myriam, La persona y sus derechos. Consideraciones bioéticas-jurídicas, Temis, Bogotá, 2000.

Kung, Hans, ¿Vida Eterna?, Trotta, Madrid, 2001.

Larrea Holguín, Juan, Derecho Constitucional, I, Corporación de Estudios y Publicaciones, Quito, 2000.

Mackie, J. L., Ética. La invención de lo bueno y lo malo, Gedisa, Barcelona, 2000. Singer, Peter, Compendio de Ética, Alianza, Madrid, 1995.

Varios autores, 39 Cuestiones doctrinales, Palabra, Madrid, 1995.

Varios autores, Cuestiones morales, Trotta, Madrid, 1996.

Varios autores, Diccionario teológico enciclopédico, Verbo Divino, Pamplona, 1995. 